\title{
JURNAL TEKNOLOGI
}

http://jurnalftijayabaya.ac.id/index.php/JTek

DOI: https://doi.org/10.31479/jtek.v9i1.132

\section{Analisa Pengaruh Pola Operasi Terhadap Laju Keausan Carbon Strip pada Pantograf}

\author{
Tri Surawan ${ }^{1)}$, Nani Kurniawati ${ }^{1, *)}$, Aji Digdoyo ${ }^{\text {1) }}$, Hanif Sujatmika ${ }^{1)}$, dan Harini Agusta ${ }^{2)}$ \\ ${ }^{1}$ Jurusan Teknik Mesin, Fakultas Teknik Industri, Universitas Jayabaya, Jakarta \\ ${ }^{2}$ Jurusan Teknik Kimia, Fakultas Teknik Industri, Universitas Jayabaya, Jakarta \\ *) Corresponding author: nanikurniawati0104@gmail.com.
}

(Received: 29 Oct 2021 • Revised: 28 Nov 2021 • Accepted: 28 Nov 2021)

\begin{abstract}
One of the components of the train system is the carbon strip on the pantograph, which serves to maximize the intake of electrical power from the overhead power lines to the train. Based on the recapitulation of the total cost of train maintenance, carbon strip requires a very high cost. Therefore, appropriate steps are needed to reduce the wear rate of the carbon strip so that the maintenance costs of the facilities can be reduced. Factors that affect wear are speed, pressure, surface roughness and hardness of the material. Based on the factors that affect wear, testing and various simulations are carried out in an effort to reduce the wear rate of carbon strips. The purpose of this study was to determine the effect of carbon brush wear on the maintenance pattern of the facility and the operating pattern of the facility. As a result, the main factor of wear, which is 70-76\% of the total thickness of train wear, occurs in the underground area. At a speed of $40 \mathrm{~km} / \mathrm{hour}$, the smallest wear rate is 3.2 $\mathrm{mm} / \mathrm{TS} / \mathrm{month}$. With a small wear rate, it also affects the need for carbon strips within 1 year, which is 384 carbon strips. So based on the analysis that has been done, it is necessary to apply a speed reduction in the underground area so that the wear rate of the carbon strip can be minimized.
\end{abstract}

\begin{abstract}
Abstrak
Salah satu komponen dari sistem kereta adalah carbon strip pada pantograf, yang berfungsi untuk memaksimalkan pengambilan daya listrik dari kabel listrik aliran atas ke kereta. Berdasarkan rekapitulasi biaya total perawatan kereta, carbon strip membutuhkan biaya yang sangat tinggi. Maka dibutuhkan langkah tepat untuk mengurangi laju keausan dari carbon strip agar biaya perawatan sarana bisa ditekan. Faktor-faktor yang mempengaruhi keausan adalah kecepatan, tekanan, kekasaran permukaan dan kekerasan bahan. Berdasarkan faktor yang mempengaruhi keausan maka dilakukan pengujian dan berbagai simulasi dalam upaya mengurangi laju keausan carbon strip. Tujuan penelitian ini untuk mengetahui pengaruh keausan carbon brush terhadap pola perawatan sarana dan pola operasi sarana. Hasilnya, faktor utama dari keausan sebesar $70-76 \%$ total tebal keausan kereta, terjadi pada area underground. Pada kecepatan $40 \mathrm{~km} / \mathrm{jam}$, laju keausan paling kecil yaitu sebesar 3,2 mm/ TS/ bulan. Dengan laju keausan yang kecil tersebut juga mempengaruhi kebutuhan carbon strip dalam kurun waktu 1 tahun yaitu 384 carbon strip. Sehingga berdasarkan analisa yang telah dilakukan, maka harus diterapkannya pengurangan kecepatan pada area underground agar laju keausan dari carbon strip dapat diminimalisir.
\end{abstract}

Keywords : Carbon strip, Wear Rate, Operating Pattern, Facilities, Train System 


\section{PENDAHULUAN}

Pantograf merupakan unit komponen yang digunakan pada kereta MRT Jakarta sebagai penghubung dari listrik aliran atas ke sistem kelistrikan kereta. Komponen utama yang terdapat pada pantograf dan mempunyai peranan penting yaitu carbon strip, komponen ini berhubungan langsung dengan jaringan listrik aliran atas. Permasalahan yang sedang terjadi pada kereta MRT Jakarta adalah tingginya biaya perawatan pantograf dan dibutuhkan solusi cepat guna menekan biaya perawatan dari komponen ini. Maka salah satu upaya dalam mengurangi biaya perawatan yaitu dengan mengubah pola operasi penggunaan kereta.

Akibat dari kerja dari komponen carbon strip yang bergesekan dengan Listrik Aliran Atas menyebabkan adanya pengikisan permukaan komponen atau sering disebut dengan keausan [1]. Keausan jenis ini terjadi apabila suatu partikel keras (asperity) dari material tertentu meluncur pada permukaan material lain yang lebih lunak sehingga terjadi penetrasi atau pemotongan material yang lebih lunak. Tingkat keausan pada mekanisme ini ditentukan oleh derajat kebebasan (degree of freedom) partikel keras atau asperity tersebut [2]. Setiap pantograf terdapat 4 buah main contact strip. Dimensi dari main contact strip yaitu $302.940 \mathrm{~mm} 3$. Bahan dari main contact strip yaitu metalized carbon dengan kandungan $\mathrm{Cu} 50 \%$ dan $\mathrm{C} 50 \%$, dan material ID PC78A [3]. Karbon memiliki sifat keras namum getas. Ketika dipadukan dengan logam besi (Fe), akan meningkatkan kekuatan mekanik material berupa ketahanan deformasi yang tinggi serta kekerasan permukaan dengan memperhatikan komposisi campurannya. Karbon juga memiliki titik lebur dan titik sublimasi yang tertinggi diantara unsur kimia lain [4].

Keausan terjadi apabila dua buah benda yang saling menekan dan saling bergesekan. Keausan yang lebih besar terjadi pada bahan yang lebih lunak. Faktor - faktor yang mempengaruhi keausan adalah kecepatan, tekanan, kekasaran permukaan dan kekerasan bahan [5]. Semakin besar kecepatan relatif benda yang bergesekan, maka material semakin mudah aus. Demikian pula semakin besar tekanan pada permukaan benda yang berkontak, material akan cepat aus, begitu pula sebaliknya. Keausan yang mengakibatkan berkurangnya material material pada benda akan menyebabkan kerusakan pada benda tersebut [6]. Gesekan antar permukaan juga akan menimbulkan panas yang juga mempengaruhi keausan, karena dalam kajian material disebutkan bahwa kekerasan material akan berkurang seiring meningkatnya temperatur [7].

Salah satu cara untuk mengatasi adanya keausan adalah dengan adanya pelumas. Namun gesekan antara carbon strip dengan kabel LAA (Listrik Aliran Atas) adalah gesekan suatu material tanpa pelumas sehingga termasuk dalam kategori gesekan kering (dry sliding) [8]. Untuk mendapatkan hasil penelitian lebih detail, maka perlu diperhitungkan nilai Specific Wear Rate kemudian dilanjutkan dengan menghitung nilai life time penggunaan material.

Maka dengan adanya penelitian ini, dapat diketahui faktor yang menjadi penyebab terjadinya perubahan laju keausan carbon strip pada pantograf, pengaruh laju keausan terhadap pola perawatan kereta dan pola operasi yang tepat guna mengurangi laju keausan dari carbon strip.

\section{METODE PENELITIAN}

\section{Obyek Penelitian}

Setiap pantograf terdapat 4 buah carbon strip. Dimensi dari carbon strip yaitu 302.940 $\mathrm{mm}^{3}$. Bahan dari carbon strip yaitu metalized carbon dengan kandungan $\mathrm{Cu} 50 \%$ dan $\mathrm{C} 50 \%$. Pengujian dilakukan dalam penggunaan kondisi normal, penggunaan 4 pantograf, dan kecepatan terbatas 50 - $40 \mathrm{~km} / \mathrm{jam}$. 


\section{Waktu dan Tempat Penelitian}

Penelitian ini dilaksanakan di lingkungan depo dan lintas utama PT. MRT-Jakarta pada bulan Maret 2020 hingga Januari 2021.

\section{Diagram Alir Analisa Laju Keausan Carbon Strip}

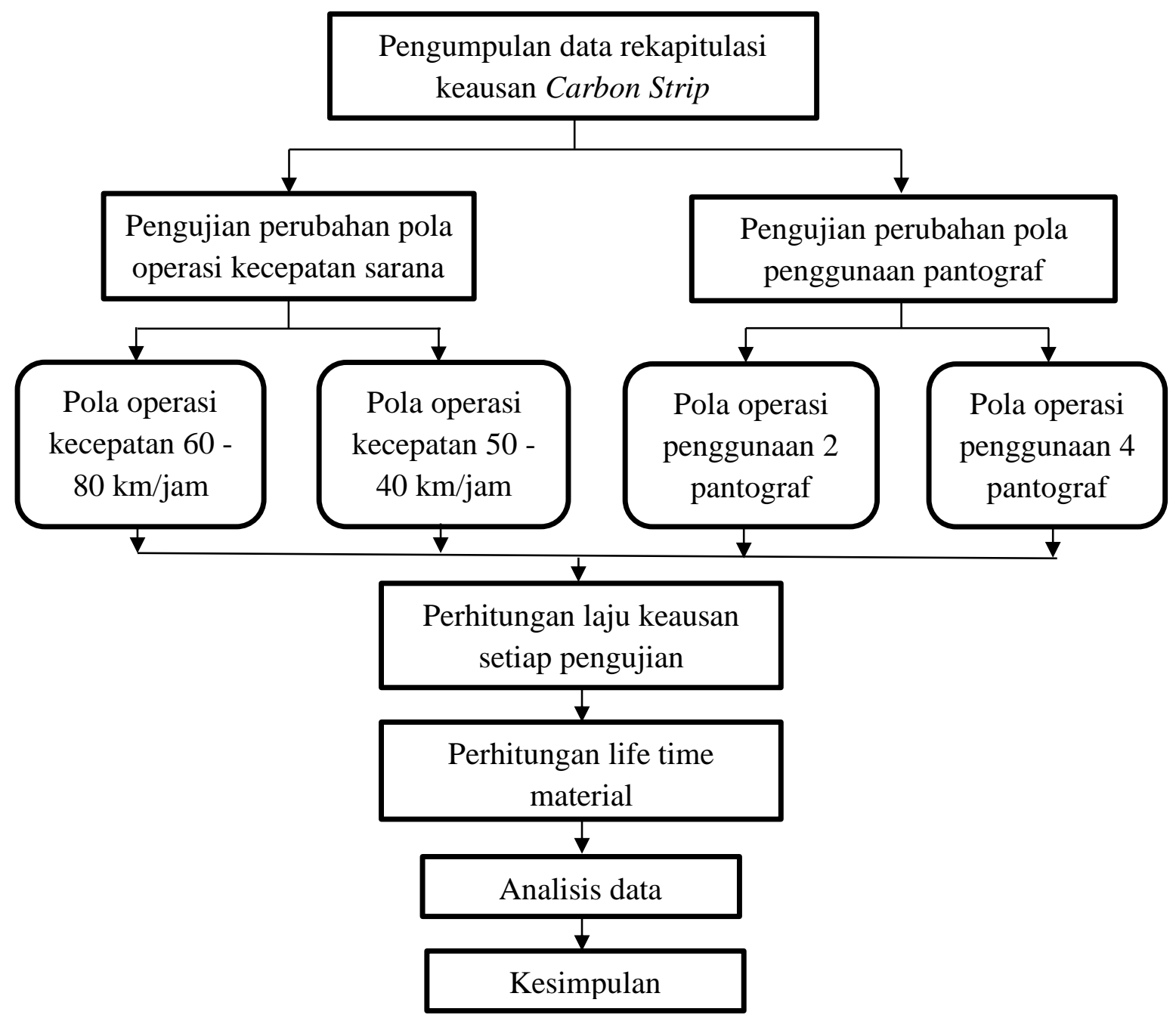

Gambar 1. Diagram Alir Analisa Laju Keausan Carbon Strip.

\section{Analisis Laju Keausan}

Dengan dilakukan analisis dari variabel yang dapat mempengaruhi keausan, maka dapat dilakukan langkah-langkah penelitian dan pembatasan masalah yang dihadapi. Variabel yang digunakan yaitu berdasarkan pola operasi yang telah diterapkan oleh PT. MRT yang terbagi menjadi 3 pola operasi : Operasi kereta normal, menggunakan 8 trainset dan berjalan dengan kecepatan antara 70-90 km/jam untuk area elevated dan kecepatan $60-80 \mathrm{~km} / \mathrm{jam}$ untuk area underground, pola pengoperasian menggunakan 4 pantograf yang dinaikkan pada area underground, dan pola operasi dalam menghadapi pandemic, yaitu dengan menurunkan kecepatan dari kereta untuk memperpanjang waktu tunggu dan headway antar kereta. Maka diterapkan kecepatan 40-50 km/jam. 


\section{Perhitungan Pengaruh Variabel Terhadap Laju Keausan}

Dalam pengujian yang dilakukan dengan berbagai metode, akan dimasukkan beberapa variabel yang menjadi pendukung dalam pengujian yang telah dilakukan. Pada penelitian ini dimasukkan pengaruh dari kecepatan, variasi tekanan dan konsumsi arus daya berdasarkan kebutuhan kecepatan pada perubahan pola operasi yang telah diterapkan. Data yang telah didapatkan akan dituangkan dalam tabel dan diagram untuk memudahkan pembacaan data yang telah dikumpulkan. Adapun perhitungan Specific Wear Rate atau laju keausan dapat dihitung dengan menggunakan persamaan [1] :

$$
K=\frac{\Delta \mathrm{V}}{\mathrm{L}}
$$

Dimana K merupakan Specific Wear Rate, V merupakan Volume material, dan L merupakan Panjang Lintasan .

\section{Perhitungan Life Time dan Kebutuhan Suku Cadang}

Setelah dilakukan pengujian dan memasukkan berbagai faktor variabel, maka data yang digunakan akan menjadi bandingan terhadap kejadian lapangan dan menentukan pengaruh antar kedua objek sebagaimana menjadi fokus penelitian ini. Setiap pengujian telah dilakukan, akan di ketahui berbagai faktor lain yang mempengaruhi dalam pengujian ini. Dan berdasarkan data tersebut maka langkah akhir adalah perhitungan kebutuhan suku cadang dalam perawatan kabel LAA dan carbon strip berdasarkan life time dari masing-masing material.n pekerjaan yang terdapat dalam penelitian ini dapat diulang sesuai dengan rincian yang disediakan. Pada bagian ini penulis menyampaikan metode penelitian/kajian yang digunakan mencakup alat, bahan, Menjelaskan dimana dan kapan penelitian dilakukan. Menjelaskan bagaimana mengambil sampel dan dianalisis dengan metode apa. Jika model matematika disajikan, penulisan rumus pada bagian ini ditulis dengan Microsoft Equation, diberi nomor urut, misal: (1), (2), ...dan seterusnya. Perhitungan Life Time dapat dihitung dengan menggunakan persamaan [3] :

$$
\text { Life time }=\frac{\mathrm{v}}{\mathrm{K}}
$$

Dimana K merupakan Specific Wear Rate, dan v merupakan volume aus.

\section{HASIL DAN PEMBAHASAN}

\section{Perhitungan Laju Keausan Carbon Strip sesuai Variabel Percobaan.}

Berdasarkan pengumpulan data keausan di lapangan, pada kedua objek uji sebagai pembanding awal sebelum dilakukannya perubahan variabel penyebab keausan. Perhitungan dilakukan dalam kurun waktu bulan November 2020 - Maret 2021. Berikut hasil pengukuran rata-rata keausan yang dilakukan pada trainset no.10, pada kereta no.13 dengan jarak tempuh rata rata $7500 \mathrm{~km}$.

Dalam keadaan normal, carbon strip memiliki volume $540 \mathrm{~mm}$ x $33 \mathrm{~mm} \times 17 \mathrm{~mm}=$ $302.940 \mathrm{~mm}^{3}$. Maka volume aus adalah hasil pengurangan dari tinggi / tebal dari carbon strip. Pola operasi yang diterapkan dalam keadaan normal adalah penggunaan 2 pantograf dengan kecepatan maksimal $100 \mathrm{~km} / \mathrm{jam}$ pada area elevated dan $80 \mathrm{~km} / \mathrm{jam}$ pada area underground. Dari Gambar 2, hasil pengujian laju keausan memperlihatkan bahwa dari bulan November 2020 sampai dengan Februari 2021 mengalami penurunan dan naik sedikit di bulan Maret 2021. 


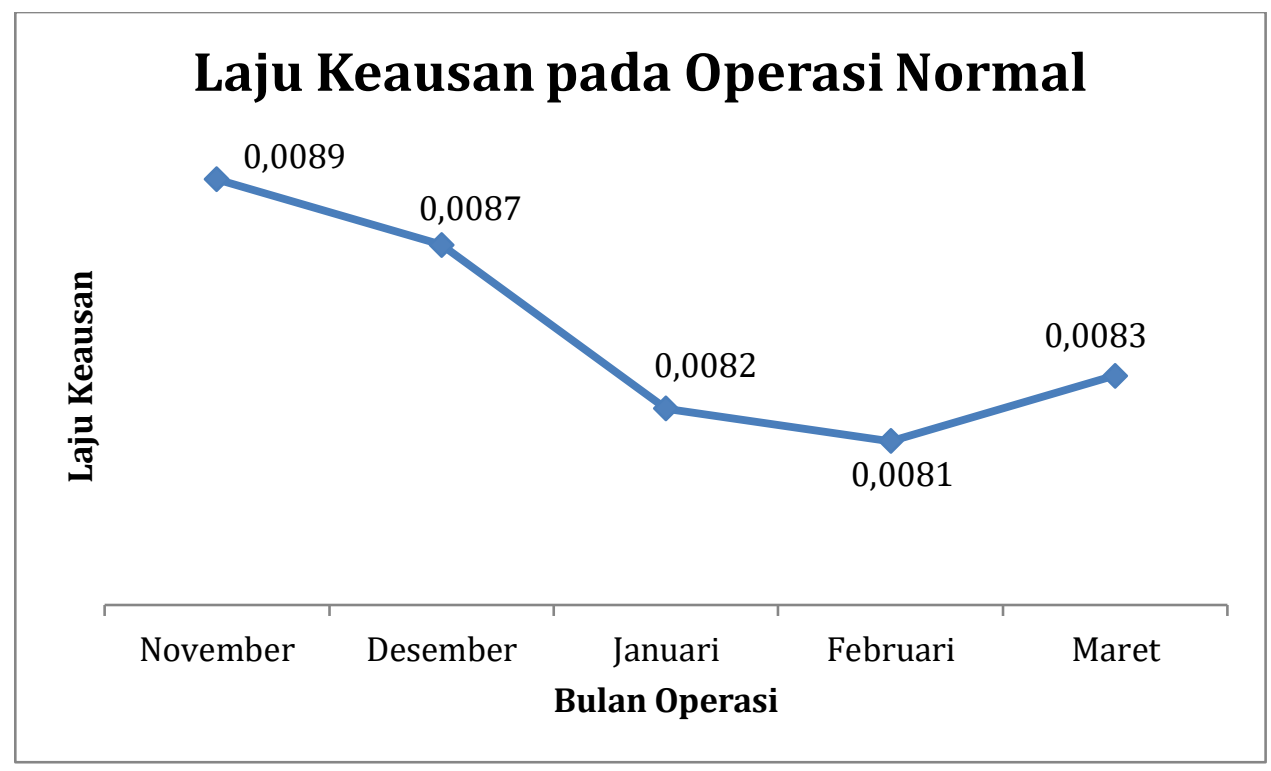

Gambar 2. Grafik laju keausan pada operasi normal

Kemudian dilakukan percobaan penggunaan 4 pantograf secara bersamaan pada area underground yang bertujuan untuk mengetahui faktor-faktor yang dapat mempengaruhi keausan dari carbon strip. Percobaan yang dilakukan adalah dengan menaikkan pantograf pada stasiun pertengahan / sebelum memasuki area underground. Percobaan ini dilakukan selama 1 bulan penuh, yang dilakukan pada kereta no. 10 dan nomor 13. Berdasarkan percobaan yang dilakukan pada semua rangkaian kereta pada periode 1 bulan, maka hasil yang didapatkan sebagai berikut :

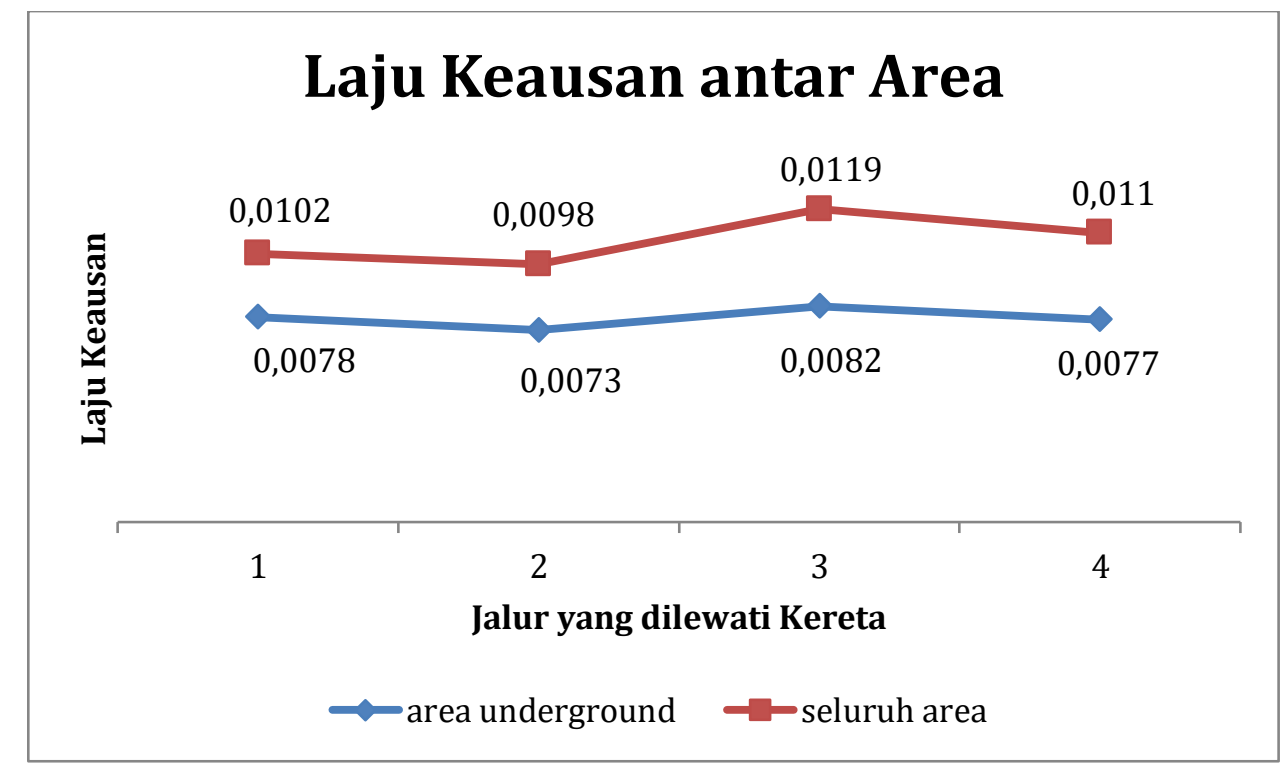

Gambar 3. Grafik laju keausan pada operasi antara area underground dan seluruh area.

Dari Gambar 3 di atas dapat dilihat bahwa perbandingan laju keausan area underground mencapai $70-76 \%$ dari keseluruhan lintas. Maka berdasarkan data tersebut, sistem catenary sangat berpengaruh terhadap laju keausan dari carbon strip. Hal ini dikarenakan, sistem catenary pada underground adalah sistem rigid. Sistem ini memiliki tingkat peredaman getaran yang lebih kecil daripada sistem catenary pada lintas elevated. Sehingga adanya perbedaan tekanan yang diberikan pada carbon strip terhadap kabel LAA begitu juga sebaliknya. 
Selain penggunaan pada 4 pantograf, dilakukan pembatasan kecepatan yang digunakan untuk bertujuan mengetahui pengaruh dari kecepatan dari sarana terhadap keausan dari kabel LAA maupun dari carbon strip pada pantograf. Pada saat kecepatan normal yang diterapkan adalah $60 \mathrm{~km} / \mathrm{jam}$ - $80 \mathrm{~km} / \mathrm{jam}$, sedangkan pada kecepatan terbatas yang dilakukan pada percobaan ini adalah $40 \mathrm{~km} / \mathrm{jam}$ - $50 \mathrm{~km} / \mathrm{jam}$. Percobaan yang dilakukan menggunakan 2 pantograf / keadaan normal. Percobaan dilakukan pada kereta no. 2, 3 dan 7 dalam periode tertentu dinasan kereta disesuaikan dengan kebutuhan jarak tempuh yang telah ditentukan agar tidak ada pengaruh eksternal lain yang bisa merubah hasil pengujian ini. Berikut hasil dari percobaan penggunaan kecepatan terbatas pada periode bulan April - Oktober 2020.

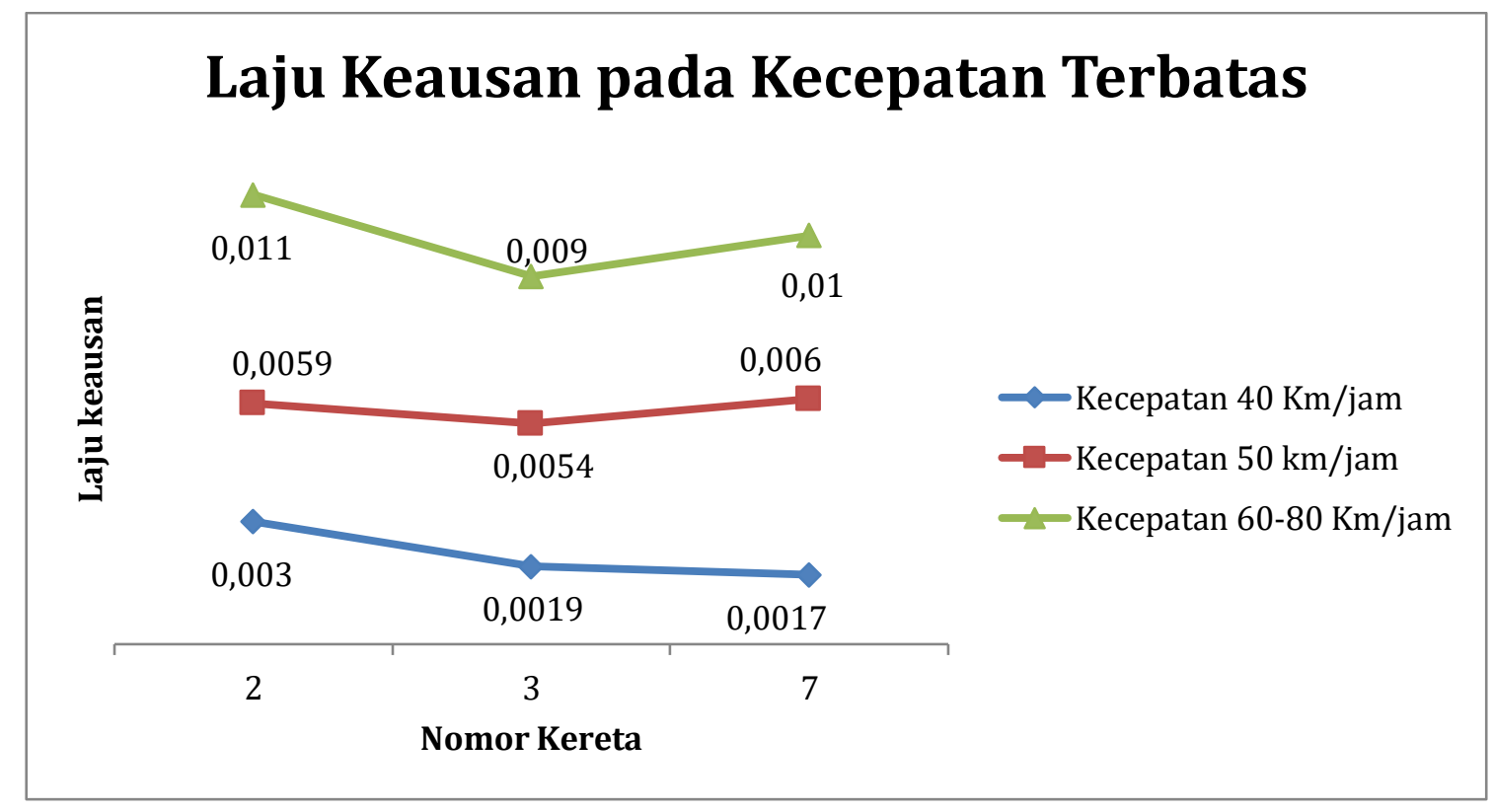

Gambar 4. Perbandingan laju keausan pada kecepatan terbatas.

Berdasarkan Gambar 4 di atas, maka kecepatan sangat berpengaruh terhadap laju keausan pada carbon strip. Pada keadaan normal dapat diambil data akumulatif bahwa keausan yang terjadi yaitu sebesar $5-7 \mathrm{~mm} / \mathrm{TS} /$ bulan. Pada kecepatan $40 \mathrm{~km} / \mathrm{jam}$ keausan akumulatif yaitu sebesar $2,3 \mathrm{~mm} / \mathrm{TS} /$ bulan. Sedangkan pada kecepatan $50 \mathrm{~km} / \mathrm{jam}$ keausan akumulatif yaitu sebesar 3,2 mm/ TS/ bulan. Hal ini disebabkan oleh perbedaan kebutuhan arus yang lebih sedikit pada penggunaan kecepatan terbatas. Dikarenakan sedikitnya jumlah arus yang dibutuhkan, maka suhu dari kedua benda yang saling bergesekan ini menurun dan menyebabkan tingkat laju keausan dari kedua material juga berkurang.

\section{Kebutuhan Carbon Strip Berdasarkan Variabel yang Ditetapkan}

Berdasarkan data laju keausan yang didapatkan pada percobaan diatas, maka dapat dilakukan perhitungan kebutuhan carbon strip dalam kurun waktu 1 tahun. Perhitungan dilakukan dengan menggunakan variabel kondisi normal, penggunaan 4 pantograf dan pembatasan kecepatan.

Berdasarkan Gambar 5 dapat diketahui bahwa pola operasi kereta mempengaruhi kebutuhan carbon strip. Kebutuhan carbon strip dalam kurun waktu 1 tahun paling sedikit pada penggunaan kecepatan $40 \mathrm{~km} / \mathrm{jam}$ dan terbesar pada penggunaan 4 pantograf. 


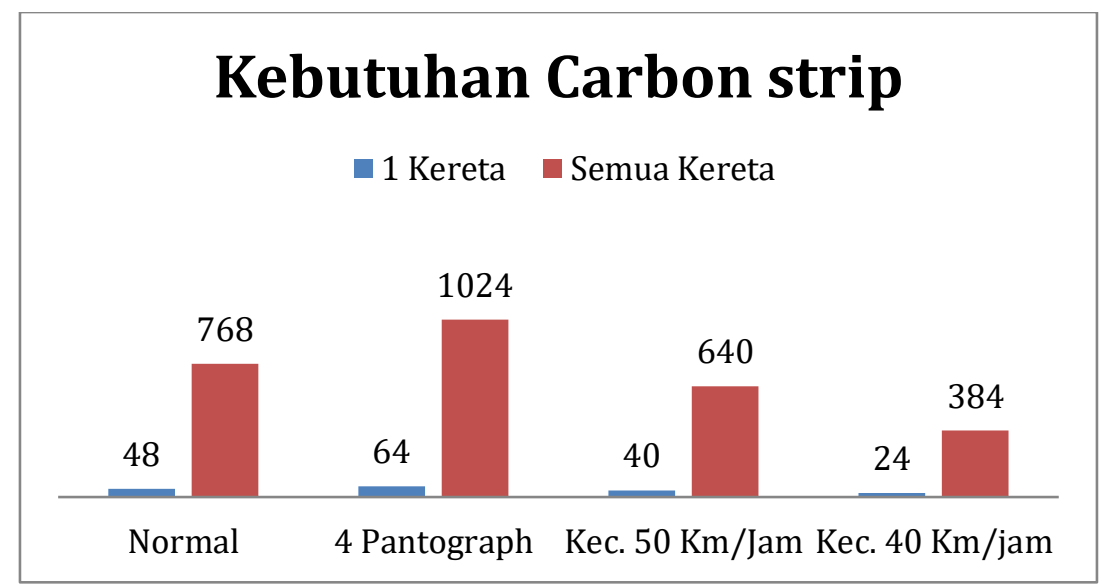

Gambar 5. Grafik kebutuhan carbon strip berdasarkan variabel laju keausan.

\section{KESIMPULAN}

Dalam pengujian yang telah dilakukan, maka faktor yang dominan mempengaruhi laju keausan pada carbon strip adalah pola operasi kecepatan kereta. Pada kecepatan $40 \mathrm{~km} / \mathrm{jam}$, laju keausan paling kecil yaitu sebesar 3,2 $\mathrm{mm} / \mathrm{TS} /$ bulan. Dengan laju keausan yang kecil tersebut juga memengaruhi kebutuhan carbon strip dalam kurun waktu 1 tahun aitu 384 carbon strip. Kebutuhan carbon strip dalam kurun waktu 1 tahun terbesar pada penggunaan 4 pantograf, yaitu 1024 carbon strip. Faktor lain yang mempengaruhi dari percobaan ini adalah jumlah penumpang yang dibawa oleh sarana. Apabila sarana membawa penumpang yang lebih banyak dan pada kecepatan yang tinggi, maka konsumsi daya yang dibutuhkan juga semakin besar. Sehingga membuat arus yang masuk melalui carbon strip dari kabel LAA menjadi lebih besar dan menimbulkan panas berlebih yang menyebabkan carbon strip dan kabel LAA mudah aus.

\section{DAFTAR PUSTAKA}

[1] T. Surawan and D. Mulyadi, "Pengaruh Waktu Pembebanan Dan Kecepatan Terhadap Keausan Paduan Tembaga (Cu) Dan Karbon (C)," Jurnal Teknologi, vol. 6, no. 2, pp. 7184, 2019.

[2] E. Gultom and Y. Kaelani, "Studi Eksperimen dan Analisa Laju Keausan Material Alternatif pada Sepatu Rem Lokomotif," Jurnal Teknik ITS, vol. 5, no. 2, 2017.

[3] A. S. Rifa'i and E. Prayogi, "Analisis Laju Keausan Main Contact Strip Pantograf Kereta PT MRT Jakarta," Jurnal of Admiration, vol. 2, no. 3, pp. 388-398, 2021.

[4] M. J. Rampe, "Konversi Arang Tempurung Kelapa Menjadi Elektroda Karbon," Chemistry Progress, vol. 8, no. 2, 2019.

[5] A. Rif'an, T. Hidayat, and R. Winarso, "Pengaruh Pelumasan Terhadap Keausan Aluminium Menggunakan Mesin Two Disk Tribometer Pada 1000 Rpm," Simetris: Jurnal Teknik Mesin, Elektro dan Ilmu Komputer, vol. 8, no. 1, pp. 273-282, 2017.

[6] D. T. Widianingrum and Y. Kaelani, "Studi Eksperimental Laju Keausan (Specific Wear 
Rate) Resin Akrilik dengan Penambahan Serat Penguat pada Dental Prosthesis," Jurnal Teknik ITS, vol. 1, no. 1, pp. B125-B129, 2012.

[7] M. Hasry and Y. Kaelani, "Studi Eksperimental Keausan Permukaan Material Akibat Adanya Multi-Directional Contact Friction," Jurnal Teknik ITS, vol. 3, no. 1, pp. B108B113, 2014.

[8] M. A. Yunan, B. Prasojo, and E. Wismawati, "Analisa Laju Erosi Dan Perhitungan Lifetime Terhadap Material Stainless Steel 304, 316, Dan 317 Pada Aliran Reject 1st Cleaner To 2nd Cleaner Occ Line Voith Unit Sp 3-5 Di PT. Pakerin (Pabrik Kertas Indonesia)," in 2nd Conference of Piping Engineering and its Application, 2017. 